\title{
Analysis on Factors Influencing Undergraduate's Learning Interest
}

\author{
Zhimin HUANG \\ Tourism Department, Inner Mongolia University of Finance and Economics, Hohhot, Inner Mongolia, China \\ zmhminmin@163.com
}

\begin{abstract}
The paper systematically analyzes potential factors influencing learning interest of university students. The sample is recruited from a survey on learning interest on students of the Grade 2013 of Institute of Tourism, Convention and Exhibition Economics and Management at Inner Mongolia University of Finance and Economics. We have found that, the recognition of the importance of expertise knowledge on future work, the interaction during teaching and learning, and the responsibility assumed by teachers, have significant positive effects on students' interest in learning. On the other hand, gender of students, adoption of new technology on teaching, and several other factors play no role on the learning interest of students.
\end{abstract}

Index Terms - Interest in learning. Influencing factors. Ordered Logistic model

\section{Introduction}

Studies of domestic scholars on students' learning interest focus on qualitative investigation for a long time, while qualitative investigation always lacks the support of data, which makes the findings of qualitative investigation lack scientific persuasiveness. In recent years, some domestic scholars began to make empirical analytical investigation to the influencing factors of learning interest and learning motivation using statistical method. However, papers which use statistical method to do such research are very few.

These scholars attribute the factors influencing students' learning interest and learning motivation to internal and external factors. For example, the empirical research made by Jiang Guodong (2012) on the learning motivation of college English listening shows that among the four dimensions of the learning motivation for listening learning, there is significant correlation between any two of learning interest, self-efficacy and level of effort, while there is no significant correlation between the learning attitude and any of the other three dimensions. The study of Yang Cuifen (2010) shows that difference exists in the learning interest of students of different grades and that outside stimulus is helpful to improve the students' learning motivation. The study of Ren Li (2010) shows that it helps to effectively enhance learning motivation by helping the students to establish appropriate learning goal, grasp the causes of success and failure, and improve learning interest and self-efficacy.

We are more likely to attribute the internal cause influencing students' learning interest to psychological factor and to attribute the external cause to external stimulus, such as the system of school and teaching. With the purpose of improving teaching method, the paper mainly explores the effect of external cause on students' learning interest in the teaching process. This paper builds models with Ordered Logistic model, and makes ordered analysis to the external causes affecting the learning interest through SPSS software to observe the effect of these factors on the learning interest so as to provide some countermeasures and suggestions for improving students' learning interest and the teaching methods.

\section{Model Building}

Ordered Logistic model is a non-linear probability model to estimate the coefficient and residual in the way of Maximum Likelihood Estimation (MLE). The model is as follows:

$$
Y_{i}^{*}=\beta^{\prime} X_{i}+\varepsilon_{i}
$$

Where, $Y_{i}^{*}$ is a dependent variable, $X_{i}$ is an independent variable, ${ }^{\varepsilon_{i}}$ is the error term, and ${ }^{\beta}$ is the estimated parameter of the model. In the model, we assume that $\varepsilon_{i}$ distributes based on Logistic. $Y_{i}^{*}$ is a latent variable, and cannot be directly observed, therefore, the probability of $Y_{i}^{*}$ has to be estimated through the observed $Y_{i}$ with the relationship between the two as follows:

$$
\begin{gathered}
Y_{i}=0 \text { if } Y_{i}^{*}<0 . \\
Y_{i}=1 ; \text { if } 0<Y_{i}^{*}<\mu_{1_{+}} \\
Y_{i}=2 \text { if } \mu_{1}<Y_{i}^{*}<\mu_{2} \\
\ldots \\
Y_{i}=J . \quad \text { if } \mu_{j-1}<Y_{i}^{*} .
\end{gathered}
$$

Where, $\mu_{i}$ is unknown, and is also the parameter to be estimated like ${ }^{\beta}$. The maximum probability of samples in each interval preference can be calculated based on ${ }^{\mu_{i}}$ and ${ }^{\beta}$. The probability distribution is shown below: 


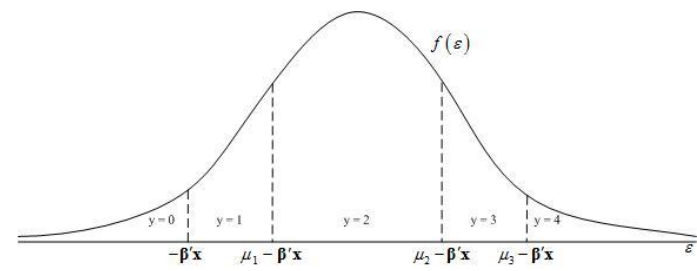

\section{Variable Selection and Data Description}

\section{A. Variable Selection}

1) Interest. We take the learning interest as the dependent variable of the model, we should take "no interest, interested, and very interested" as the standards measuring the learning interest of the major in the questionnaire because accurate data measurement to the learning interest is not easy, and take the learning interest as the ordinal variable.

2) Sex. Introduce the variable of sex to analyze the possible impact of sex on students' learning interest. Take girl as the benchmark factor, and define it as 0 ; take boy as the comparison factor, and define it as 1.

3) Effect of the knowledge of major subject. Analyze if the students' awareness of the importance of the knowledge of major subject will affect the learning interest by means of the investigation of "the effect of the knowledge of major subject on the work in the future".

4) Teaching technology. Consider the effect of application of image, picture, multimedia teaching and other technologies in teaching on students' learning interest.

5)Interaction. Consider the interaction between teachers and students in classroom teaching, for example, if classroom group discussion, asking questions in class will affect the students' learning interest.

6) Teachers' liability. Considering that the variable is difficult to measure, we describe the connotation of the variable as "if the teacher prepares for lessons carefully, the number of teacher correcting students' papers, and the enthusiasm of the teacher teaching" in the questionnaire to acquire information on teachers' sense liability so as to further analyze that if the factor will affect the students' learning interest.

\section{B. Data acquisition and description}

In order to get available data of related variables, the author conducts a survey on the learning interest of students of 2012 session majoring in exhibition economy and management of College of Tourism of Inner Mongolia University of Finance and Economics where I study in the form of questionnaire. A total of 30 questionnaires were sent out and all were got back, the recovery rate was $100 \%$, and the effective rate was $100 \%$. Prepare six questions according to the selected variables, and each question can get $\leq 30$ answer(s) (1, 2...).

Table 1 is the descriptive statistics of related variables in the sample which includes a total of 30 observed values. Overall, in the 30 observation objects, for "students' learning interest in their major", $6.7 \%$ of the students choose "very interested", $83.3 \%$ of the students choose "interested", and only $10 \%$ of the students choose "no interest", which indicates that the vast majority of the students of the class maintains bigger interest; for sex, in the 30 observation objects, women account for $80 \%$, and men account for $20 \%$; for "the effect of the knowledge of event management on your work in the future", $26.75 \%$ of the students choose "very helpful", $70.0 \%$ of the students choose "a little helpful", and 3.3\% of the students choose "no help"; for "the effect of application of image, picture, multimedia teaching and other technologies on your learning interest in classroom teaching", $46.7 \%$ of the students choose "very important", $50.0 \%$ of the students choose "important", and 3.3\% of the students choose "no importance"; for "the effect of the interaction between teachers and students in classroom teaching on your learning interest", $46.7 \%$ of the students believe "very useful", $46.7 \%$ of the students think "a little useful", and $6.7 \%$ of the students think "no use"; for "the effect of teachers' liability on your learning interest", $76.7 \%$ of the students choose "very influential", $23.3 \%$ of the students choose "more or less influential", and no one choose "no influence".

TABLE I Statistical description of sample data

\begin{tabular}{|c|c|c|c|}
\hline Variable & Variable value & $\mathrm{N}$ & Marginal percentage \\
\hline \multirow{3}{*}{$\begin{array}{l}\text { Interest (dependent } \\
\text { variable) }\end{array}$} & .00 & 3 & $10.0 \%$ \\
\hline & 1.00 & 25 & $83.3 \%$ \\
\hline & 2.00 & 2 & $6.7 \%$ \\
\hline \multirow{2}{*}{ sex } & .00 & 24 & $80.0 \%$ \\
\hline & 1.00 & 6 & $20.0 \%$ \\
\hline \multirow{3}{*}{ effect } & 1.00 & 8 & $26.7 \%$ \\
\hline & 2.00 & 21 & $70.0 \%$ \\
\hline & 3.00 & 1 & $3.3 \%$ \\
\hline \multirow{3}{*}{ technology } & 1.00 & 14 & $46.7 \%$ \\
\hline & 2.00 & 15 & $50.0 \%$ \\
\hline & 3.00 & 1 & $3.3 \%$ \\
\hline \multirow{3}{*}{ interaction } & 1.00 & 14 & $46.7 \%$ \\
\hline & 2.00 & 14 & $46.7 \%$ \\
\hline & 3.00 & 2 & $6.7 \%$ \\
\hline \multirow{2}{*}{ liability } & 1.00 & 23 & $76.7 \%$ \\
\hline & 2.00 & 7 & $23.3 \%$ \\
\hline & Valid & 30 & $100.0 \%$ \\
\hline & Missing & 0 & \\
\hline & Total & 30 & \\
\hline
\end{tabular}

\section{Statistical Analysis}

We take interest as the explained variable (dependent variable), and get the regression result in Table 2 by 
conducting ordered regression in the environment of SPSS with ORD:

TABLE II Ordered Logistic regression result

\begin{tabular}{|c|c|c|c|c|c|c|}
\hline & $\begin{array}{c}\text { Symbolic } \\
\text { representation }\end{array}$ & $\begin{array}{c}\text { Estimated } \\
\text { value }\end{array}$ & $\begin{array}{c}\text { Standard } \\
\text { error }\end{array}$ & Wald & $\mathrm{df}$ & $\begin{array}{c}\text { Significanc } \\
\mathrm{e}\end{array}$ \\
\hline \multirow{13}{*}{$\begin{array}{c}\text { Independe } \\
\text { nt } \\
\text { variables }\end{array}$} & {$[\operatorname{sex}=.00]$} & 2.379 & 1.837 & 1.677 & 1 & .195 \\
\hline & {$[\operatorname{sex}=1.00]$} & $0 \mathrm{a}$ & . & . & 0 & . \\
\hline & [effect=1.00] & 17.003 & 1.328 & 163.982 & 1 & .000 \\
\hline & [effect=2.00] & 18.164 & .000 & . & 1 & . \\
\hline & [effect=3.00] & $0 \mathrm{a}$ & . & . & 0 & . \\
\hline & [technology $=1.00]$ & .588 & 4.143 & .020 & 1 & .887 \\
\hline & {$[$ technology $=2.00]$} & .955 & 3.973 & .058 & 1 & .810 \\
\hline & {$[$ technology $=3.00]$} & $0 \mathrm{a}$ & . & . & 0 & . \\
\hline & [interaction $=1.00]$ & 1.289 & 0.405 & 10.129 & 1 & .001 \\
\hline & {$[$ interaction $=2.00]$} & 1.157 & 0.402 & 8.283 & 1 & .003 \\
\hline & [interaction $=3.00]$ & $0 \mathrm{a}$ & . & . & 0 & . \\
\hline & [liability $=1.00]$ & .785 & 0.261 & 9.046 & 1 & .002 \\
\hline & [liability =2.00] & $0 \mathrm{a}$ & . & . & 0 & . \\
\hline \multicolumn{7}{|c|}{ Connectivity function: Logit. } \\
\hline
\end{tabular}

It can be seen from the estimated value that girls' learning interest in the major is higher than that of boys. However, the regression coefficient about sex is not significant, indicating that sex is of no significant influence on students' learning interest. The regression coefficient about effect is very significant, which indicates that the importance of the effect of the professional knowledge learned on the future work will significantly affect the students' learning interest. The regression coefficient of technology is not significant, indicating that the effect of using teaching technologies on students' learning interest is not significant. The regression coefficient of interaction is very significant, indicating that teaching interaction has a significant influence on students' learning interest. The regression coefficient of liability is very significant, indicating that teachers' sense of liability has a significant influence on students' learning interest.

\section{Conclusions and Suggestions}

We can get the following conclusions and suggestions according to the regression result:

1) Cognition of the effect of the knowledge of professional course on the future work will significantly affect students' learning interest. At present, the theory divorced from practice in professional course of many universities, therefore, the problem that the professional knowledge learned in university is not applied in practical work becomes more and more prominent, resulting in reduction of students' learning interest. As a result of the influence of social environment, students tend to have more and more impetuous psychology, and usually believe that they should learn "useful knowledge" in the limited time, and simply give up "useless knowledge". This requires universities setting professional curriculum more scientifically, and combining with actual social need. On the one hand, universities can establish professional training centers to make students understand the professional knowledge and use the whole process through simulation teaching. On the other hand, universities should take the practical teaching mode of "university-industry cooperation", arrange the students to practice through cooperation with relevant enterprises, teach in production and operating activities of enterprises according to practical problems.

2) Teaching interaction has a significant effect on the students' learning interest. It shows that traditional "irrigation" and "cramming" teaching mode is difficult to stimulate students' learning interest, and university teachers need to continuously improve their teaching methods, and apply more teaching interactions in classroom teaching so as to arouse the students' learning interest in boring theory.

3) Teachers' liability, such as the degree of carefulness of lesson preparation of teachers, the originality of the teaching content, and the degree of teachers' enthusiasm in teaching also have a significant positive impact on students' learning interest. As a subjective factor, liability is difficult to measure and monitor, therefore, it needs universities improve and perfect teaching supervising mechanism to strengthen teachers' liability.

This study aims to conduct science statistics to the external factors affecting students' learning interest, especially the teaching factor through statistical research methods to provide certain reference for the improvement of the teaching method. What needs to be stated is that the following defects exist in the study: 1. Some omissions exist in the selection of independent variables; 2 . There are fewer respondents, which affects the accuracy of the result.

\section{References}

[1] Jiang Guodong. Empirical Study on the Learning Motivation of College English Listening,, Journal of Hangzhou Dianzi University (Social Science Edition), Issue 02 of 2012.

[2] Yang Cuifen. Empirical Study on Students' Learning Motivation, Journal of Shanxi University of Finance and Economics (Higher Education Edition), Issue 02 of 2010.

[3] Ren Li. Empirical Study on Improving Independent Learning Motivation, Journal of Anhui University of Technology (Social Science Edition), Issue 01 of 2010. 